\title{
The use of electronic journals for the dissemination of scholarly information by the University of Natal and the University of Zululand
}

\author{
Margaret N. Mgobozi \\ University of Zululand Library \\ e-mail: mmgobozi@pan.uzulu.ac.za \\ Dennis N. Ocholla \\ e-mail: docholla@pan.uzulu.ac.za
}

Department of Library and Information Science, University of Zululand

\begin{abstract}
Received: 5th August 2002
Revised: 2nd September 2002

The study investigates the use of electronic journals for the dissemination of scholarly information in the Universities of Natal and Zululand. It attempts to determine the level of use of electronic journals by the scholarly communities, and the perceived impact that these journals have on the community. Similarly, the role played by the academic libraries in the provision of these journals was explored. The scholarly community included the academic staff, the library staff and postgraduate students. A survey research method was used to elicit information from the respondents. The population was sampled using the stratified random sampling technique. A sample of $10 \%$ was drawn from the population of 1969 postgraduate students. Regarding the academic staff a sample of $20 \%$ was drawn from each stratum. The total population for the academic staff was 557. All professional librarians in the two university libraries were identified and included in the study. Data was analysed by means of the SYSTAT Version 7.0 and Microsoft Excel. The findings indicate that the level of electronic journal use by the two universities is low despite their historical differences in resource support. It is recommended that the academic library should provide facilities where users can access electronic journals on their own. The librarians should also market their services and products to library clientele. There is a need for user education, especially in the use of electronic journals. The study provides interesting insights on the theme.
\end{abstract}

\section{Introduction}

The increase of electronic journals suggests that they are popular for scientific communication among members of the academic community. Arguably, electronic journals have an impact on scholarly communication as they offer many potential benefits including prompt full-text accessibility. It is essential to understand the perceived impact these journals have on the university academic environment as a whole, as this has implications on cost reduction, learning process, budgeting, research and effective information dissemination. It is believed that some academics recognise and use the electronic journals effectively more than others who could be unaware of their existence and hence rely largely on the print journals for scholarly work at additional cost. One of the authors who is a subject librarian at the University of Zululand usually communicates with students and staff who need scholarly information from the library. Information in the form of electronic journal articles, and other electronic resources such as newspapers and full-text articles, is retrieved and either printed or e-mailed to the user. It is believed that users such as the academic staff and students who have direct access to the Internet might not come to the library, but might do their own information searches and achieve reasonable retrieval success. However, it was speculated that the use and exploitation of electronic journals at an Historically Advantaged University such as the University of Natal would be much higher than that of an Historically Disadvantaged University such as the University of Zululand. This could be largely due to disparities in infrastructural and resource support, location and attitude in favour of the University of Natal. This study was to determine and compare the use of electronic journals by the scholarly community in the two universities, in terms of the level of electronic journals use, their perceived impact and attitudes of end-users. It explored also the disparities in use and exploitation of the journals, role of academic libraries, resource support to electronic journal exploitation and whether there is any relationship between research and publication output by staff and the use of either print or electronic journals.

\section{Review of the literature}

Electronic journals are serial publications that are available in digital format. These journals may be distributed in various ways, such as on CD-ROM and the Internet. Those delivered through the Internet are available through World Wide Web and E-mail. There are some which use formats such as Adobe's PDF. Some are purely electronic, while others also 
appear in print form. Users have free access to some electronic journals while they have to subscribe to others (Klemperer, 1999). Although some electronic journals are electronic in form they do index or review paper-based publications (Mogge, 1999:20). Electronic journals may be divided into three types, e.g. online, CD-ROM and web-based electronic journals. Online electronic journals, according to Sweeney (1997), are “... pay as you go ..." Powerful searching tools are used to retrieve information from online journals. These journals are printed on paper and thereafter scanned, stored and distributed electronically. The entire issue may be distributed electronically to a membership list, or only the table of contents and abstracts may be provided, with specific information on how to obtain the full electronic text of an article. According to Rao (1998) these are digitised journals. CD-ROMs tend to be electronic versions of the existing printed journals. Web-based electronic journals, as observed by Rao (1998), are electronic journals that are digital in form. These are produced, processed, edited, stored, reviewed and distributed to subscribers electronically without print versions.

Electronic journals offer many solutions to problems currently facing information management centres. Firstly, they save space, as their storage is more efficient than having shelf-space for a number of volumes (Bandyopadhay, I999; Cook, 1992:33; and Sweeney, 1997). Secondly, electronic journals improve the speed of communication by providing updates on recently published material and allowing for swift transmission of research results and scholarly communication (Sweeney 1997; Rao 1998 and Mountifield \& Van Brakel 1994). Chan (I999) concurs that electronic transmission of journals saves valuable time, more especially with the review process, thus establishing network communication among authors, editors and referees. Thirdly, electronic journals provide powerful searching tools. Words and terms in the records on the database can be searched and combined with the help of the Boolean operators (AND, NOT, OR). Specific periods or years can also be used to broaden or narrow the search (Fisher 1995). Several databases can be searched simultaneously, allowing large collections of material to be retrieved instantly. Fourthly, they provide immediate access to needed information (Fisher 1995, Sweeney 1997 \& Bandyopadhay 1999). Rao (1998) reinforces that electronic journals facilitate precise access to the archive of knowledge. Thus, finding articles or journals can take minutes or even seconds rather than longer waiting periods encountered with printed journals (Chan 1999). Lastly, electronic journals are cost effective as far as the printing of paper and mailing to subscribers is concerned (Rao 1998). Academic and public institutions are faced with budget cuts whereby they are required to cancel subscriptions on a number of journals. Information published in electronic journals tends to be up-to-date, as there are no printing and distribution delays. Rao (1998) emphasises that published electronic articles may be available within forty-eight hours after being approved by the pre-view team.

Evidently, there are still problems related to the advent of electronic journals and their use. For storage and display electronic journals rely on technology and equipment that is rather expensive and not affordable by poor users (Chan 1999). Computer literacy is still a problem. Though information delivered electronically may be cheap, the cost of computer hardware needed is high (Sweeney 1997). Files that are transferred electronically also cause network problems. The speed and bandwidth of networks could be affected, as electronic journals become more technologically advanced. Electronic interfaces can take a long time to master, thus frustrating end-users. Some electronic journals are not free and they do charge subscription fees (Chan 1999). Mackay (1999) cautions that to receive access to electronic journals at no additional charge, academic institutions need to subscribe to the print versions. Thus, in order for academic institutions to gain access to every electronic journal published, they need to subscribe to a number of aggregator services as well as multiple publishers.

The electronic journals may be an answer to the problem of information overload where the scholarly community is finding difficulty keeping pace with developments in their various disciplines. Accessing information from their place of work is therefore an advantage. Electronic journals are said to provide continuous and instant access to relevant material (Eason, Carter and Harker 1997).

Van der Walt \& van Brakel (1995:57-63) give the following as methods that may be used for accessing electronic journals: personal electronic communication where electronic mail is used to transfer messages between users. Electronic journals may also be distributed in this format. Electronic list managers are also useful in distributing content pages and individual articles to subscribers. Internet facilities are used for transferring information and the use of files between different sites of PCs. The file transfer protocol FTP is used for the physical retrieval of archived issues of electronic journals. Direct access to specific titles including databases of solely electronic journals is available to the users.

Studies on attitude and usage of electronic journals by, for example, Harter (1998), Milne (I999), Cargille, Degener, Barker and Huang (1999), Gyeszly (200I:5), Liew, Foo and Chennupati (2000:302) focusing on academics, library staff and students, recognise increased popularity of electronic journals among the academic community. Electronic journals play a crucial role in scholarly communication. Ocholla (1999:12) pinpoints that academics are involved with scientific activities and communication in addition to their academic activities. They are, he notes, engaged in academic research, 
participate in conferences, seminars and workshops, conduct research, prepare and report research results, publish and teach. These academic activities are therefore part of formal and informal scholarly communication. Kuhlen and Zhang (1997) state that scholarly literature is an essential element of the scholarly communication system and argue that it is the formal form and basis of scientific communication.

According to Eason, Carter \& Harker (1997) formal communication is a public and permanent record of the achievements of the discipline. It is a peer reviewed, quality assured record, which meets the performance criteria of the discipline. It may also be a record which obeys the specialist conventions and language of the discipline, which facilitates swift communication with fellow scholars. It is a statement of the current state of knowledge in the discipline. It also provides a place for authors to register their achievements, by which means they may be assessed by colleagues for career progression, status in the field, and serve as a means of attracting new recruits (Eason, Carter \& Harker, 1997).

Studies confirm that scholarly communities and academic libraries are important role players in the system of scholarly communication (Milne, 1999). This could be attributed to the fact as observed by Ocholla (1999:122) that universities expect academics to conduct research, publish, teach, participate in academic administration and be involved in community development. Varian (1997) also notes that the academic reward system is structured to encourage the production and dissemination of good ideas that are widely read and acknowledged. The three main roles of scholarly communication as identified by Getz (1997) are teaching, provision of knowledge to the community, and developing new knowledge.

The mission statements of the two institutions under investigation support these roles of scholarly communication, which are the following:

The University of Natal strives to serve all sections of its community through excellence in scholarship, teaching, learning, research and development (University of Natal, 200 Ib). The University of Natal Library's mission in turn is to provide resources and information services that will support the learning, teaching, research and development endeavours of the University community (University of Natal, 2000). Similarly, the University of Zululand is committed to provide Tertiary Education and to pursue knowledge, which serves the needs of the country in general and those of the surrounding communities in particular (University of Zululand, 200 la). The University of Zululand Library's mission is to serve the teaching, learning and research functions of the university, as well as the needs of the community in its immediate vicinity who can benefit from it without prejudicing the privileges of its primary clientele (University of Zululand, 2000a).

The academics are faced with challenges such as a professional, career-oriented occupation that requires them to look for information (Ocholla, 1999:135). Evidently, the scholarly community of the two institutions (Universities of Natal and Zululand) pursue higher academic qualifications such as masters or doctorate degrees that force them to continue to look for information besides what is required for their traditional academic responsibilities.

Studies show that scholarly journals play an important role in the dissemination of scholarly information (Varian I997; Eason, Carter \& Harker 1997; Wells 1999; Harter, 1998:507; Milne 1999; Oppenheim, Greenhalgh \& Rowland, 2000:36I). This role is clearly articulated by Harter (1998:507) who reiterates that the scholarly journal has served as the primary medium of scholarly communication among scholars for more than three centuries, and has remained basically unchanged in form and function since its inception. This role, however, differs from discipline to discipline. Some disciplines use journals more for information dissemination, while others rely on books (Ocholla, 1999:136). Harter (1998:507) further observes that, despite the popularity of the printed journal, it has been criticised due to a number of problems. Peer-review process, high costs that are growing much faster than the rate of inflation and the lack of selectivity are widely criticised. Notwithstanding the said criticism Harter (1998:507) observes that the explosion of the Internet and the development of the World Wide Web created an opportunity for the development of the electronic journals.

It is believed that electronic journals will transform the scholarly communication system (Harter, 1998:507). Electronic journals, he advises, can only succeed in this transformation if they are integrated in the process of scholarly communication. This in essence creates new challenges to the academic scholars to read and write articles to be published in electronic journals, because without their active contribution in terms of readership and authorship electronic journals cannot prosper. Harter (1998:508) advises that scholars must be influenced or affected by the findings reported so as to build or modify their own research and scholarship on the content of electronic journal articles. Oppenheim, Greenhalgh and Rowland (2000:365) add that scholarly inquiry in the new medium of electronic journals will proceed much more quickly, interactively and globally, and might become a lot more participatory. 


\section{Methodology}

In this study 308 questionnaires were distributed to academics and postgraduate students and 34 to the library staff. The University of Zululand and the University of Natal (Durban and Pietermaritzburg) scholarly community made up the study population. Five faculties were selected for sampling purposes. These were the faculties of Arts (UZ), Commerce and Administration (UZ), Law (UN) and (UZ) and Science and Agriculture from both institutions. The aim was to include faculties with more or less similar disciplines. The University of Zululand scholarly community consisted of 196 academic staff, 426 postgraduate students and 34 library staff (University of Zululand, 200la and University of Zululand, the Division of Information Technology Department $200 \mathrm{lb}$ ). The number of students included the main campus and Durban Umlazi Campus (DUC) only. The University of Natal scholarly community consisted of $36 \mathrm{I}$ academic staff, 1543 postgraduate students, and 87 library staff (University of Natal, 200la). The sample size for academic staff was $20 \%$ whereas that of the postgraduate students was $10 \%$. The sample size drawn for the academic staff at the University of Zululand was 39 , which was $20 \%$ of 196 , while that of the University of Natal was 72 , being $20 \%$ of 36 I. The sample size for the postgraduate students at the University of Zululand was 43 , being $10 \%$ of 426 , while that of the University of Natal was 154, being $10 \%$ of 1543. In case of the library staff all professional librarians from the two institutions were included in the survey.

The questionnaires were administered to various groups through e-mail, internal mail and also distributed by hand. The majority of those which were distributed by hand to the postgraduates of the University of Natal were supplied with self-addressed envelopes in order to encourage easy postage. Other questionnaires were distributed through Heads of Department to the postgraduate students. The reason for this was that there was no usable list for the postgraduate students. Questionnaires were administered from July $200 \mathrm{I}$ to the first week of October 200I. The first group of questionnaires was administered to the library staff of the University of Natal in Durban. The Library Staff of Durban Umlazi Campus Library, which is a branch library of the University of Zululand Academic Library, were also approached to complete the questionnaires and to distribute and receive questionnaires from the postgraduate students at DUC. These were returned by inter-university mail to the researcher. Both the questionnaires to library staff at Pietermaritzburg and to the academic staff at the University of Natal and Zululand were sent by electronic mail in August 200I. The e-mails were sent with an attachment containing the file containing the questionnaire. The respondent could easily open the attachment, supply the required information, and return the questionnaire by e-mail, but others preferred to print them and return questionnaires in hard copy by mail. Responses that were received through e-mail were transferred and saved in a separate file for easy retrieval and printing. Responses from postgraduate students were separated according to institutional affiliation, faculties and level of study. They were then arranged separately for sampling purposes.

A pilot study was conducted in May 200 I with 23 respondents from the University of Zululand population, consisting of 10 academic staff members, 3 professional librarians, and 10 postgraduate students. This preliminary study was extremely helpful in testing and adjusting the research instrument. The quantitative data was analysed largely by means of the SYSTAT Version 7.0 and Microsoft Excel for coding data. A section of the report has been analysed by qualitative techniques.

It was difficult to obtain a usable list of the postgraduate students for sampling purposes before the distribution of the questionnaires, unlike the sampling of the academic staff respondents. Non-response therefore could not be easily traced.

\section{Research results}

The first set consisting of 308 questionnaires was administered to the academic staff and postgraduate students. The second set of 34 questionnaires was administered to the library staff. $168(54 \%)$ responses were received from the first set whereas 22 (65\%) were received from the second set. A 100\% response was not received from the academic staff in both institutions, postgraduate students from the University of Natal and Library Staff from both institutions. The nonresponse in some cases was attributed to non-use of electronic journals. Both sets of questionnaires consisted of both closed questions, approximately $80 \%$ for the first set and $62 \%$ for the second set; and open-ended questions, $20 \%$ for the first set and $38 \%$ for the second set.

4.1 Responses from the academic staff and postgraduate students

This section comprises the personal information, which identifies the respondents according to their institutional affiliation, faculty, academic status, and level of study. Information that follows relates to the use of scholarly journals, electronic journals, and recommendations made by respondents 


\section{I.I Institutional affiliation}

Responses received were 168, 50 (30\%) from the academic staff and 118 (70\%) from the postgraduate students. Responses are summarised in Table I below:

Table I. Institutional affiliation $(\mathbf{N}=\mathbf{3 0 8})$

\begin{tabular}{|c|c|c|c|c|c|c|c|c|c|c|c|c|c|c|}
\hline \multirow[t]{3}{*}{ Institutional Affiliation } & \multicolumn{4}{|c|}{ Academic Staff } & \multicolumn{4}{|c|}{ Postgraduate Students } & \multicolumn{4}{|c|}{ Total } & \multirow{2}{*}{\multicolumn{2}{|c|}{\begin{tabular}{|l|} 
Overall \\
$N=308$
\end{tabular}}} \\
\hline & \multicolumn{2}{|c|}{$\mathrm{UN}=72$} & \multicolumn{2}{|c|}{$U Z=39$} & \multicolumn{2}{|c|}{$U N=154$} & \multicolumn{2}{|c|}{$\mathrm{UZ}=43$} & \multicolumn{2}{|c|}{$U N=226$} & \multicolumn{2}{|c|}{$U Z=82$} & & \\
\hline & $N$ & $\%$ & $N$ & $\%$ & $N$ & $\%$ & $\mathrm{~N}$ & $\%$ & $N$ & $\%$ & $N$ & $\%$ & $\mathrm{~N}$ & $\%$ \\
\hline Responses received & 31 & 43 & 19 & 49 & 75 & 49 & 43 & 100 & 106 & 47 & 62 & 76 & 168 & 55 \\
\hline No response & 41 & 57 & 20 & 51 & 79 & 51 & 0 & 0 & 120 & 53 & 20 & 24 & 140 & 45 \\
\hline Total & 72 & 100 & 39 & 100 & 154 & 100 & 43 & 100 & 226 & 100 & 82 & 100 & 308 & 100 \\
\hline
\end{tabular}

\section{I.2 Faculty}

The distribution of responses showed that $36(21 \%)$ responses were received from the Faculty of Arts, 7 (4\%) from the Faculty of Commerce and Administration, 64 (38\%) from the Faculty of the Human Sciences, II (7\%) from the Faculty of Law and 50 (30\%) from the Faculty of Science and Agriculture.

\section{I.3 Academic status / Rank of the academic staff}

Out of 50 respondents II were professors, 6 associate professors, 14 senior lecturers, 15 lecturers and 4 researchers. A sample of $20 \%$, representing 39 respondents from the University of Zululand, and 72 respondents from the University of Natal, was drawn for the academic staff. Four faculties were selected from the University of Zululand and three from the University of Natal. Faculties selected included the Faculty of Arts, Commerce and Administration, Human Sciences, Law and Science and Agriculture. The total number of academic staff members in these faculties was 196 from the University of Zululand and 360 from the University of Natal. Because of the enormous difference in population numbers between the University of Zululand and the University of Natal, the number of respondents looks very odd; however, a sample of $20 \%$ was used for each faculty.

\section{I.4 Level of study}

The respondents from both institutions were II $18(75=64 \%(\mathrm{UN})$ and $43=35 \%(\mathrm{UZ}))$. Out of II 8 respondents 52 (44\%) were honours students, $47(40 \%)$ masters students and $19(16 \%)$ were doctoral students. Because of the difference in student numbers between the two institutions a sample of $10 \%$ was used from each faculty to ensure equal distribution. The response rate at the University of Zululand was $100 \%$ as compared to a response rate of $49 \%$ at the University of Natal. The required sample for the University of Natal was I54 but 75 responses were received, resulting in a $49 \%$ response rate.

The results appear very strange, as there are faculties represented by I respondent or 5 respondents only. The reason for this is similar to the one mentioned for the academic staff. The population from the two institutions is not the same and there appears to be a large difference between the number of registered students.

\subsection{Use of scholarly journals}

Out of 168 respondents 148 (88\%) responses were received in relation to the use of scholarly journals. 17 (I0\%) respondents said that they were not using scholarly journals while $3(2 \%)$ did not respond to the question. This question was asked in order to determine the level of use between traditional scholarly journals and electronic journals. Another aim was to indicate to those who were using scholarly journals to continue to Section 2 . Results are summarised in table 2 below.

Table 2. Use of scholarly journals $(\mathrm{N}=168)$

\begin{tabular}{|c|c|c|c|c|c|c|c|c|c|c|c|c|c|c|}
\hline & \multicolumn{4}{|c|}{ Academic Staff } & \multicolumn{4}{|c|}{ Postgraduate students } & \multicolumn{4}{|c|}{ Total } & \multirow{2}{*}{\multicolumn{2}{|c|}{$\begin{array}{l}\text { Overall } \\
N=168\end{array}$}} \\
\hline & \multicolumn{2}{|c|}{$U N=31$} & \multicolumn{2}{|c|}{$U Z=19$} & \multicolumn{2}{|c|}{$\mathrm{UN}=75$} & \multicolumn{2}{|c|}{$U Z=43$} & \multicolumn{2}{|c|}{$U N=106$} & \multicolumn{2}{|c|}{$\mathrm{UZ}=62$} & & \\
\hline & $N$ & $\%$ & $N$ & $\%$ & $\mathrm{~N}$ & $\%$ & $N$ & $\%$ & $\mathrm{~N}$ & $\%$ & $N$ & $\%$ & $\mathrm{~N}$ & $\%$ \\
\hline Yes & 31 & 100 & 19 & 100 & 71 & 95 & 27 & 63 & 102 & 96 & 46 & 74 & 148 & 88 \\
\hline No & 0 & 0 & 0 & 0 & 4 & 5 & 13 & 30 & 4 & 4 & 13 & 21 & 17 & 10 \\
\hline No response & 0 & 0 & 0 & 0 & 0 & 0 & 3 & 7 & 0 & 0 & 3 & 5 & 3 & 2 \\
\hline Total & 31 & 100 & 19 & 100 & 75 & 100 & 43 & 100 & 106 & 100 & 62 & 100 & 168 & 100 \\
\hline
\end{tabular}


Responses from all academic staff from both institutions indicated a 100\% use of scholarly journals. 7I (95\%) responses from postgraduate students from the University of Natal and 27 (63\%) from the University of Zululand also indicated the use of scholarly journals. The production of non-use was lower at the University of Natal with $4(5 \%)$ as compared to a non-use of $13(30 \%)$ at the University of Zululand and a non-response of $7 \%$. The overall proportion of non-use from both institutions was therefore 20 (I2\%).

\subsection{Purpose of using scholarly journals}

This section required the respondents to indicate the purpose for which they use scholarly journals. They were given multiple choice options where they could choose more than one purpose between teaching, research, learning and other. The purpose of asking this question was to determine the dependence on traditional scholarly journals by the scholarly community. Because of 20 (I2\%) respondents who indicated a non-use of scholarly journals the target number for this question was 148, 102 at the University of Natal and 46 at the University of Zululand. The respondents were required to select one or more options for this question. From Table 3 above it looks as if a very low number was received for using scholarly journals for teaching purposes whereas it was selected with other options. Academic respondents, for instance, selected teaching and research whereas postgraduate respondents selected research and learning. Of course, learning is a holistic concept that embodies both teaching and research. The percentage of respondents who selected teaching only was very low as compared to other purposes. More respondents 65 (44\%) indicated multiple purposes of using scholarly journals. The University of Zululand was the highest by $54 \%$ in selecting more choices that include teaching, research and learning whereas the University of Natal scored $39 \%$ in this selection. The academic staff respondents were higher than postgraduate students in using scholarly journals for multiple purposes. The results reflect $61 \%$ against $21 \%$ at the University of Natal and $79 \%$ against $37 \%$ at the University of Zululand. Results according to faculties show that the Faculty of Law (UN) uses scholarly journals by $50 \%$ more than other faculties for research whereas Law (UZ) uses them more for learning purposes than other faculties. The Faculty of Commerce and Administration (UZ) was the highest by $100 \%$ in indicating more choices, followed by the Faculty of Science and Agriculture. (UZ) with 60\%, followed by the Faculty of Law (UZ) with 50\%, Human Sciences (UN) with 47\%, Arts (UZ) with $46 \%$, Science and Agriculture (UN) with $30 \%$ and Law (UN) with 12\%. Results are summarised in Table 3.

4.4. Type of scholarly journals used most

This section required respondents to indicate the type of scholarly journals that they use most. The item aimed at probing further about the type of scholarly journals that the scholarly community depends on. The target respondents for this question were those who had responded that they use scholarly journals, therefore the target group was I48, 46 (3I\%) for the University of Zululand and $102(69 \%)$ for the University of Natal. The results presented for academic and postgraduate students are combined, but separated according to faculties, and by academic status, that is, academic or postgraduate students from the same institution, then according to the institution. Results show that the scholarly community of these institutions is still dependent on the printed journals for their scholarly activities. It is further noted that the Faculty of Law in both institutions is still dependent on the use of printed journals. The Faculty of Law (UZ) scored $100 \%$ while that of UN scored $75 \%$. The Arts Faculty followed with $73 \%$, Commerce and Administration and Science and Agriculture (UZ) both with 67\%, followed by Science and Agriculture (UN) with 61\%. The Faculty of the Human Sciences at the University of Natal, though also dependent on the printed journals, was the lowest amongst the group with $52 \%$. This faculty scored higher than the others did in selecting both electronic and printed journals by $44 \%$, followed by the Faculty of Science (UN) with 39\%. The faculties of Commerce and Administration and Science and Agriculture scored $33 \%$. The faculties of Arts and the Human Sciences indicated that they use electronic journals but on a very low scale of $8 \%$ and $2 \%$ respectively. Results show that the overall usage of electronic journals is $2 \%$ for both institutions as compared to $61 \%$ for printed journals. The use of both electronic and print journals scored $36 \%$, which is much lower than that of the print journals alone. The University of Zululand scholarly community (72\%) is more dependent on print journals than the University of Natal (57\%). The University of Zululand academic staff uses printed journals by $69 \%$ whereas that of the University of Natal uses them by $65 \%$, which exhibits insignificant difference. The postgraduate students of the University of Zululand also use printed journals by $74 \%$ whereas postgraduate students from the University of Natal use them by $54 \%$. Results are summarised in Table 4. 
Table 3. Purpose of using scholarly journals $(\mathbf{N}=148)$

\begin{tabular}{|c|c|c|c|c|c|c|c|c|c|c|c|c|c|c|c|c|c|c|c|c|c|c|c|c|}
\hline \multirow[t]{3}{*}{$\begin{array}{l}\text { Purpose } \\
\text { of using } \\
\text { scholarly } \\
\text { journals }\end{array}$} & \multirow{2}{*}{\multicolumn{2}{|c|}{$\begin{array}{l}\text { Arts } \\
(\mathrm{UZZ}) \\
\mathrm{N}=26\end{array}$}} & \multirow{2}{*}{\multicolumn{2}{|c|}{$\begin{array}{l}\text { Commerce } \\
\text { \& Admin } \\
\text { (UZ) }\end{array}$}} & \multirow{2}{*}{\multicolumn{2}{|c|}{$\begin{array}{l}\text { Human } \\
\text { Sciences } \\
\text { (UN) }\end{array}$}} & \multirow{2}{*}{\multicolumn{2}{|c|}{\begin{tabular}{|l} 
Law \\
$(\mathrm{UN})$
\end{tabular}}} & \multirow{2}{*}{\multicolumn{2}{|c|}{$\begin{array}{l}\text { Law } \\
(\mathrm{UZ})\end{array}$}} & \multirow{2}{*}{\multicolumn{2}{|c|}{$\begin{array}{l}\text { Science } \\
\& \text { Agri- } \\
\text { culture } \\
(\mathrm{UN})\end{array}$}} & \multirow{2}{*}{\multicolumn{2}{|c|}{\begin{tabular}{|l}
$\begin{array}{l}\text { Science } \\
\text { \& Agri- } \\
\text { culture } \\
(\mathrm{UZ})\end{array}$ \\
$\mathrm{N}=15$ \\
\end{tabular}}} & \multicolumn{4}{|c|}{ Academic Staff } & \multicolumn{4}{|c|}{$\begin{array}{l}\text { Postgraduate } \\
\text { Students }\end{array}$} & \multirow{2}{*}{\multicolumn{2}{|c|}{$\begin{array}{l}\text { TOTAL } \\
\mathrm{N}=148\end{array}$}} \\
\hline & & & & & & & & & & & & & & & $N=$ & & UN & $=19$ & $\mathrm{UZ}=$ & $=71$ & UN & $=27$ & & \\
\hline & $\mathrm{N}$ & $\%$ & $\mathrm{~N}$ & $\%$ & $N$ & $\%$ & $N$ & $\%$ & $N$ & $\%$ & $N$ & $\%$ & $\mathrm{~N}$ & $\%$ & $N$ & $\%$ & $\mathrm{~N}$ & $\%$ & $N$ & $\%$ & $\mathrm{~N}$ & $\%$ & $N$ & $\%$ \\
\hline Teaching & 2 & 8 & 0 & 0 & I & 2 & 0 & 0 & 0 & 0 & 0 & 0 & 0 & 0 & 1 & 3 & 1 & 5 & 0 & 0 & I & 4 & 3 & 2 \\
\hline Research & 8 & 31 & 0 & $\sigma$ & 16 & 26 & 4 & 50 & 0 & 0 & 16 & 49 & 6 & 40 & 11 & 36 & 3 & 16 & 25 & 35 & 11 & 41 & 50 & 34 \\
\hline Learning & 4 & 15 & 0 & 0 & 14 & 23 & 3 & 38 & I & 50 & 6 & 18 & 0 & 0 & 0 & 0 & 0 & 0 & 23 & 32 & 5 & 18 & 28 & 19 \\
\hline ices & 12 & 46 & 3 & 100 & 29 & 47 & I & 12 & I & 50 & 10 & 30 & 9 & 60 & 19 & 61 & 15 & 79 & 21 & 31 & 10 & 37 & 65 & 44 \\
\hline Other & 0 & 0 & 0 & 0 & 0 & 0 & 0 & 0 & 0 & 0 & I & 3 & 0 & 0 & 0 & 0 & 0 & 0 & I & I & 0 & 0 & I & 1 \\
\hline $\begin{array}{l}\text { No } \\
\text { response }\end{array}$ & 0 & 0 & 0 & 0 & 0 & I & 2 & 0 & 0 & 0 & 0 & 0 & 0 & 0 & 0 & 0 & 0 & 0 & I & I & 0 & 0 & I & I \\
\hline TOTAL & 26 & 100 & 3 & 100 & 61 & 100 & 8 & 100 & & 100 & 33 & 100 & 15 & 100 & 31 & 100 & 19 & 100 & 71 & 100 & 27 & 100 & 148 & 100 \\
\hline
\end{tabular}

Table 4. Type of scholarly journals used most $(\mathbf{N}=148)$

\begin{tabular}{|c|c|c|c|c|c|c|c|c|c|c|c|c|c|c|c|c|c|c|c|c|c|c|c|c|}
\hline \multirow[t]{3}{*}{$\begin{array}{l}\text { Type of } \\
\text { journals } \\
\text { used }\end{array}$} & \multirow{2}{*}{\multicolumn{2}{|c|}{$\begin{array}{l}\text { Arts (UZ) } \\
N=26\end{array}$}} & \multirow{2}{*}{\multicolumn{2}{|c|}{$\begin{array}{l}\text { Commerce } \\
\text { \& Admin } \\
\text { (UZ) } \\
\mathrm{N}=3\end{array}$}} & \multirow{2}{*}{\multicolumn{2}{|c|}{$\begin{array}{l}\text { Human } \\
\text { Sciences } \\
\text { (UN) } \\
\mathrm{N}=6 \mathrm{I}\end{array}$}} & \multirow{2}{*}{\multicolumn{2}{|c|}{$\begin{array}{l}\text { Law } \\
(\mathrm{UN})\end{array}$}} & \multirow{2}{*}{\multicolumn{2}{|c|}{$\begin{array}{l}\text { Law } \\
\text { (UZ) } \\
\mathrm{N}=2\end{array}$}} & \multirow{2}{*}{\multicolumn{2}{|c|}{$\begin{array}{l}\text { Science } \\
\& \text { Agri- } \\
\text { culture } \\
(\mathrm{UN}) \\
\mathrm{N}=33\end{array}$}} & \multirow{2}{*}{\multicolumn{2}{|c|}{$\begin{array}{l}\text { Science } \\
\& \text { Agri- } \\
\text { culture } \\
(\mathrm{UZ}) \\
\mathrm{N}=15\end{array}$}} & \multicolumn{4}{|c|}{ Academic Staff } & \multicolumn{4}{|c|}{$\begin{array}{l}\text { Postgraduate } \\
\text { Students }\end{array}$} & \multirow{2}{*}{\multicolumn{2}{|c|}{$\begin{array}{l}\text { Total } \\
N=148\end{array}$}} \\
\hline & & & & & & & & & & & & & & & \multicolumn{2}{|c|}{$U N=31$} & \multicolumn{2}{|c|}{$U Z=19$} & \multicolumn{2}{|c|}{$U N=7 I$} & \multicolumn{2}{|c|}{$U Z=27$} & & \\
\hline & $\mathrm{N}$ & $\%$ & $N$ & $\%$ & $\mathrm{~N}$ & $\%$ & $\mathrm{~N}$ & $\%$ & $\mathrm{~N}$ & $\%$ & $\mathrm{~N}$ & $\%$ & $\mathrm{~N}$ & $\%$ & $\mathrm{~N}$ & $\%$ & $\mathrm{~N}$ & $\%$ & $\mathrm{~N}$ & $\%$ & $\mathrm{~N}$ & $\%$ & $\mathrm{~N}$ & $\%$ \\
\hline Electronic & 2 & 8 & 0 & 0 & I & 2 & 0 & 0 & 0 & 0 & 0 & 0 & 0 & 0 & 0 & 0 & I & 5 & I & I & I & 4 & 3 & 2 \\
\hline Printed & 19 & 73 & 2 & 67 & 32 & 52 & 6 & 75 & 2 & 100 & 20 & 61 & 10 & 65 & 20 & 65 & 13 & 69 & 38 & 54 & 20 & 74 & 91 & 61 \\
\hline Both & 5 & 19 & 1 & 33 & 27 & 44 & 2 & 25 & 0 & 0 & 13 & 39 & 5 & 33 & 11 & 35 & 5 & 26 & 31 & 44 & 6 & 22 & 53 & 36 \\
\hline $\begin{array}{l}\text { No } \\
\text { response }\end{array}$ & 0 & 0 & 0 & 0 & I & 2 & 0 & 0 & 0 & 0 & 0 & 0 & 0 & 0 & 0 & 0 & 0 & 0 & I & I & 0 & 0 & I & I \\
\hline TOTAL & 26 & 100 & 3 & 100 & 61 & 100 & 8 & 100 & 2 & 100 & 33 & 100 & 15 & 100 & 31 & 100 & 19 & 100 & 71 & 100 & 27 & 100 & 148 & 100 \\
\hline
\end{tabular}

\subsection{Awareness of the availability of electronic journals}

This was the first question of section two of the questionnaire. This question was intended to determine the level of understanding of electronic journals because a user who knows nothing about electronic journals may not be in a position to know about their availability or non-availability. However, the fact that users could be aware of the availability of electronic journals or any other services but still did not use them for certain reasons, could not be underestimated. The target group of respondents for this question was 148 , who had indicated that they were using scholarly journals. This number consisted of 46 (31\%) respondents from the University of Zululand, and 102 (69\%) from the University of Natal. Results reflect a response rate of $138(93 \%)$ awareness of the availability of electronic journals, and $10(7 \%)$ of either not aware or no response. The faculties of Commerce and Administration, Law (UN) and (UZ), Science and Agriculture $(\mathrm{UN})$ and $(\mathrm{UZ})$ all scored $100 \%$ in the awareness of the availability of electronic journals. The faculties of Arts and Human Sciences had $10(7 \%)$ respondents who were either not aware or did not respond to the question. The overall response rate was 138 (93\%).

\subsection{The use of electronic journals}

The question targeted 138 respondents, 96 (70\%) respondents from the University of Natal and 42 (30\%) from the University of Zululand. Respondents were required to choose between yes and no to indicate their use or non-use of electronic journals. The response rate was $110(80 \%)$. The non-use of electronic journals was $28(20 \%)$ from both institutions. The results in Table 5 reflect a $100 \%$ use of electronic journals from the Faculty of Commerce and Administration, followed by the Faculty of Science and Agriculture (UZ) by $93 \%$, Human Sciences by $87 \%$, Arts by $82 \%$, Law (UN) by $75 \%$, Science and Agriculture (UN) by $64 \%$. The faculty of Law (UZ) scored $50 \%$. The overall use was $80 \%$ while non-use was $20 \%$. Results are summarised in Table 5. 
Table 5. The use of electronic journals $(\mathrm{N}=138)$

\begin{tabular}{|c|c|c|c|c|c|c|c|c|c|c|c|c|c|c|c|c|c|c|c|c|c|c|c|c|}
\hline $\begin{array}{l}\text { Use of } \\
\text { electronic } \\
\text { journals }\end{array}$ & \multicolumn{2}{|c|}{$\begin{array}{l}\text { Arts } \\
\text { (UZ) }\end{array}$} & \multicolumn{2}{|c|}{$\begin{array}{l}\text { Commerce } \\
\text { \& Admin } \\
(\mathrm{UZ})\end{array}$} & \multicolumn{2}{|c|}{$\begin{array}{l}\text { Human } \\
\text { Sciences } \\
(\mathrm{UN})\end{array}$} & \multicolumn{2}{|c|}{$\begin{array}{l}\text { Law } \\
\text { (UN) }\end{array}$} & \multirow{2}{*}{\multicolumn{2}{|c|}{$\begin{array}{l}\text { Law } \\
(\mathrm{UZ}) \\
\mathrm{N}=2\end{array}$}} & \multirow{2}{*}{\multicolumn{2}{|c|}{\begin{tabular}{|l} 
Science \\
\& Agri- \\
culture \\
(UN)
\end{tabular}}} & \multirow{2}{*}{\multicolumn{2}{|c|}{$\begin{array}{l}\begin{array}{l}\text { Science } \\
\text { \& Agri- } \\
\text { culture } \\
(\mathrm{UZ})\end{array} \\
\mathrm{N}=15\end{array}$}} & \multicolumn{4}{|c|}{ Academic Staff } & \multicolumn{4}{|c|}{$\begin{array}{l}\text { Postgraduate } \\
\text { Students }\end{array}$} & \multirow{2}{*}{\multicolumn{2}{|c|}{$\begin{array}{l}\text { TOTAL } \\
\mathrm{N}=138\end{array}$}} \\
\hline & $N=$ & & $\mathrm{N}=$ & & $\mathrm{N}=\mathrm{s}$ & & $N=$ & & & & & & & & \multicolumn{2}{|c|}{$U N=30$} & \multicolumn{2}{|c|}{$U Z=18$} & \multicolumn{2}{|c|}{$U N=66$} & \multicolumn{2}{|c|}{$\mathrm{UZ}=24$} & & \\
\hline & $\mathrm{N}$ & $\%$ & $\mathrm{~N}$ & $\%$ & $\mathrm{~N}$ & $\%$ & $\mathrm{~N}$ & $\%$ & $\mathrm{~N}$ & $\%$ & $\mathrm{~N}$ & $\%$ & $N$ & $\%$ & $\mathrm{~N}$ & $\%$ & $\mathrm{~N}$ & $\%$ & $N$ & $\%$ & $\mathrm{~N}$ & $\%$ & $\mathrm{~N}$ & $\%$ \\
\hline Yes & 17 & 82 & 3 & 100 & 48 & 87 & 6 & 75 & I & 50 & 21 & 64 & 14 & 93 & 24 & 80 & 15 & 83 & 51 & 77 & 20 & 83 & 110 & 80 \\
\hline No & 5 & 18 & 0 & 0 & 7 & 13 & 2 & 25 & I & 50 & 12 & 36 & I & 7 & 6 & 20 & 3 & 17 & 15 & 23 & 4 & 17 & 28 & 20 \\
\hline TOTAL & 22 & 100 & 3 & 100 & 55 & 100 & 8 & 100 & 2 & 100 & 33 & 100 & 15 & 100 & 30 & 100 & 18 & 100 & 66 & 100 & 24 & 100 & 138 & 100 \\
\hline
\end{tabular}

Table 6. Purpose of using electronic journals $(\mathrm{N}=110)$

\begin{tabular}{|c|c|c|c|c|c|c|c|c|c|c|c|c|c|c|c|c|c|c|c|c|c|c|c|c|}
\hline \multirow[t]{3}{*}{$\begin{array}{l}\text { Purpose } \\
\text { of } \\
\text { electronic } \\
\text { journals }\end{array}$} & \multirow{2}{*}{\multicolumn{2}{|c|}{$\begin{array}{l}\text { Arts (UZ) } \\
\mathrm{N}=17\end{array}$}} & \multirow{2}{*}{\multicolumn{2}{|c|}{$\begin{array}{l}\text { Commerce } \\
\text { \& Admin } \\
\text { (UZ) } \\
\mathrm{N}=3\end{array}$}} & \multirow{2}{*}{\multicolumn{2}{|c|}{\begin{tabular}{|l}
$\begin{array}{l}\text { Human } \\
\text { Sciences } \\
\text { (UN) }\end{array}$ \\
$\mathrm{N}=48$
\end{tabular}}} & \multirow{2}{*}{\multicolumn{2}{|c|}{\begin{tabular}{|l} 
Law \\
$(\mathrm{UN})$
\end{tabular}}} & \multirow{2}{*}{\multicolumn{2}{|c|}{\begin{tabular}{|l} 
Law \\
$(\mathrm{UZ})$
\end{tabular}}} & \multirow{2}{*}{\multicolumn{2}{|c|}{\begin{tabular}{|l|}
$\begin{array}{l}\text { Science } \\
\text { \& Agri- } \\
\text { culture } \\
(\mathrm{UN})\end{array}$ \\
$\mathrm{N}=21$
\end{tabular}}} & \multirow{2}{*}{\multicolumn{2}{|c|}{\begin{tabular}{|l}
$\begin{array}{l}\text { Science } \\
\& \text { Agri- } \\
\text { culture } \\
(U Z)\end{array}$ \\
$N=14$
\end{tabular}}} & \multicolumn{4}{|c|}{ Academic Staff } & \multicolumn{4}{|c|}{$\begin{array}{l}\text { Postgraduate } \\
\text { students }\end{array}$} & \multirow{2}{*}{\multicolumn{2}{|c|}{$\begin{array}{l}\text { TOTAL } \\
\mathrm{N}=1 \mathrm{I} 0\end{array}$}} \\
\hline & & & & & & & & & & & & & & & \multicolumn{2}{|c|}{$U N=24$} & \multicolumn{2}{|c|}{$U Z=15$} & \multicolumn{2}{|c|}{$N=5 I$} & \multicolumn{2}{|c|}{$N=20$} & & \\
\hline & $N$ & $\%$ & $N$ & $\%$ & $N$ & $\%$ & $N$ & $\%$ & $N$ & $\%$ & $N$ & $\%$ & $N$ & $\%$ & $N$ & $\%$ & $\mathrm{~N}$ & $\%$ & $N$ & $\%$ & $\mathrm{~N}$ & $\%$ & $N$ & $\%$ \\
\hline Research & 9 & 53 & 0 & 0 & 16 & 31 & 4 & 67 & I & 100 & 10 & 48 & 10 & 71 & 14 & 58 & 10 & 67 & 16 & 31 & 10 & 50 & 50 & 45 \\
\hline Learning & I & 6 & 1 & 33 & 12 & 25 & I & 10.5 & 0 & 0 & 3 & 14 & 1 & 7 & 0 & 0 & 0 & 0 & 16 & 31 & 3 & 15 & 19 & 17 \\
\hline $\begin{array}{l}\text { Multiple } \\
\text { choices }\end{array}$ & 6 & 35 & 2 & 67 & 17 & 36 & 0 & 0 & 0 & 0 & 8 & 38 & 3 & 21 & 10 & 42 & 5 & 33 & 15 & 29 & 6 & 30 & 36 & 33 \\
\hline $\begin{array}{l}\text { No } \\
\text { response }\end{array}$ & I & 6 & 0 & 0 & 3 & 6 & 1 & 10.5 & 0 & 0 & 0 & 0 & 0 & 0 & 0 & 0 & 0 & 0 & 4 & 8 & 1 & 5 & 5 & 5 \\
\hline TOTAL & 17 & 100 & 3 & 100 & 48 & 100 & 6 & 100 & I & 100 & 21 & 100 & 14 & 100 & 24 & 100 & 15 & 100 & 51 & 100 & 20 & 100 & 110 & 100 \\
\hline
\end{tabular}

Table 7. Use of electronic journals for the dissemination of scholarly information $(\mathbf{N}=110)$

\begin{tabular}{|c|c|c|c|c|c|c|c|c|c|c|c|c|c|c|c|c|c|c|c|c|c|c|c|c|}
\hline \multirow[t]{3}{*}{$\begin{array}{l}\text { Dissemi- } \\
\text { nation of } \\
\text { infor- } \\
\text { mation }\end{array}$} & \multirow{2}{*}{\multicolumn{2}{|c|}{$\begin{array}{l}\begin{array}{l}\text { Arts } \\
(\mathrm{UZ})\end{array} \\
\mathrm{N}=17\end{array}$}} & \multirow{2}{*}{\multicolumn{2}{|c|}{$\begin{array}{l}\begin{array}{l}\text { Commerc } \\
\text { e \& Admin } \\
\text { (UZ) }\end{array} \\
\mathrm{N}=3\end{array}$}} & \multirow{2}{*}{\multicolumn{2}{|c|}{\begin{tabular}{|l}
$\begin{array}{l}\text { Human } \\
\text { Sciences } \\
\text { (UN) }\end{array}$ \\
$\mathrm{N}=48$
\end{tabular}}} & \multirow{2}{*}{\multicolumn{2}{|c|}{$\begin{array}{l}\text { Law } \\
(\mathrm{UN}) \\
\mathrm{N}=6\end{array}$}} & \multirow{2}{*}{\multicolumn{2}{|c|}{$\begin{array}{l}\text { Law } \\
\text { (UZ) } \\
\mathrm{N}=\mathrm{I}\end{array}$}} & \multirow{2}{*}{\multicolumn{2}{|c|}{$\begin{array}{l}\text { Science } \\
\& \text { Agri- } \\
\text { culture } \\
(\mathrm{UN}) \\
\mathrm{N}=2 \mathrm{I}\end{array}$}} & \multirow{2}{*}{\multicolumn{2}{|c|}{\begin{tabular}{|l}
$\begin{array}{l}\text { Science } \\
\text { \& Agri- } \\
\text { culture } \\
(\mathrm{UZ})\end{array}$ \\
$\mathrm{N}=14$
\end{tabular}}} & \multicolumn{4}{|c|}{ Academic Staff } & \multicolumn{4}{|c|}{$\begin{array}{l}\text { Postgraduate } \\
\text { Students }\end{array}$} & \multirow{2}{*}{\multicolumn{2}{|c|}{$\begin{array}{l}\text { TOTAL } \\
\mathrm{N}=110\end{array}$}} \\
\hline & & & & & & & & & & & & & & & \multicolumn{2}{|c|}{$U N=24$} & \multicolumn{2}{|c|}{$U Z=15$} & \multicolumn{2}{|c|}{$N=5 I$} & \multicolumn{2}{|c|}{$\mathrm{N}=20$} & & \\
\hline & $\mathrm{N}$ & $\%$ & $N$ & $\%$ & $N$ & $\%$ & $\mathrm{~N}$ & $\%$ & $\mathrm{~N}$ & $\%$ & $\mathrm{~N}$ & $\%$ & $N$ & $\%$ & $N$ & $\%$ & $\mathrm{~N}$ & $\%$ & $N$ & $\%$ & $\mathrm{~N}$ & $\%$ & $N$ & $\%$ \\
\hline Yes & & 65 & 2 & 67 & 34 & 71 & 4 & 67 & 0 & 0 & 18 & 86 & 10 & 71 & 23 & 96 & 14 & 93 & 31 & 61 & 11 & 55 & 79 & 72 \\
\hline No & 6 & 35 & 1 & 33 & 14 & 29 & 2 & 33 & 1 & 100 & 3 & 14 & 3 & 21 & I & 4 & 1 & 7 & 20 & 39 & 8 & 40 & 30 & 27 \\
\hline $\begin{array}{l}\text { No } \\
\text { response }\end{array}$ & 0 & 0 & 0 & 0 & 0 & 0 & 0 & 0 & 0 & 0 & 0 & 0 & 1 & 7 & 0 & 0 & 0 & 0 & 0 & 0 & I & 5 & I & 1 \\
\hline TOTAL & 17 & 100 & 3 & 100 & 48 & 100 & 6 & 100 & I & 100 & 21 & 100 & 14 & 100 & 24 & 100 & 15 & 100 & 51 & 100 & 20 & 100 & 110 & 100 \\
\hline
\end{tabular}

\subsection{Purpose of using electronic journals}

Respondents who had indicated that they were not using electronic journals were excluded from this question which required purposes of using electronic journals. The target number of respondents was 110 (80\%) comprising 35 (32\%) from the University of Zululand and 75 (68\%) from the University of Natal. The response rate was $44 \%$ for research, $38 \%$ for multiple choice, which consisted of either two or three choices between the three options, and $15 \%$ for learning which was selected more often by the postgraduate students. Results summarised in Table 6 reflect that the Faculties of Law (UZ), Science and Agriculture (UZ) and Law (UN) scored more in using electronic journals for research purposes. Other faculties spread their purposes in all the options. Teaching was removed from the table because it was not selected alone as research and learning, but was always combined with other options. It may not be reflected in the table but it was also selected. Research as a purpose of using electronic journals was selected more by the academic staff respondents of the University of Zululand, $67 \%$ as compared to $58 \%$, whereas those of the University of Natal selected a multiple option more than the University of Zululand, i.e. $42 \%$ and $33 \%$. 


\subsubsection{Use of electronic journals for the dissemination of scholarly information}

Respondents were required to indicate if they use electronic journals for the dissemination of information. The Faculty of Science and Agriculture (UN) use electronic journals for the dissemination of scholarly information by $86 \%$. The Faculty of Human Sciences and Science and Agriculture (UZ) follow by $71 \%$, and the Faculty of Commerce and Administration and Law (UN) by 67\%, Faculty of Arts by 65\%. Results are summarised in Table 7.

4.7 Type of electronic information that is normally used

This section was meant to find out the type of electronic information that is normally used by the respondents. They were given multiple selection between 'full-text', 'abstracts', 'bibliographic information' and 'other'. Results reflect that respondents use all three types more as they scored $41 \%$ in the use of the combination of three suggested types of information. The Faculty of Science and Agriculture (UN) use full-text articles more than other faculties by $48 \%$, followed by Law $(\mathrm{UN})$ and Commerce and Administration with $33 \%$. The respondents also selected more choices, which included two or three of the selections. The Faculty of Law (UZ) selected more choices by $100 \%$, followed by the Faculty of Arts with $47 \%$.

\subsection{Academic library and electronic journals}

This item was meant to test the knowledge of respondents concerning the provision of electronic journals by their academic libraries. They were therefore asked if their academic libraries offer electronic journals. The overall response rate indicated that $71 \%$ felt that their academic libraries do offer electronic journals; $4 \%$ said that the library does not offer electronic journals, while $24 \%$ did not respond.

The postgraduate students respondents of the University of Natal were the highest with $88 \%$ indicating that their academic library offers electronic journals, followed by their academic staff represented by $63 \%$, postgraduate students, of the University of Zululand by $60 \%$ and lastly, the academic staff of the University of Zululand by $40 \%$.

\subsection{I.The resource support for accessibility offered by academic libraries}

Respondents were given options to indicate the resource support offered by academic libraries for electronic journal accessibility. The suggestions were excellent, sufficient, minimal and undecided. The target group for this question was 78 $(71 \%)$ respondents who had indicated that their academic libraries offer electronic journals. These were $60(77 \%)$ from the University of Natal and 18 (23\%) from the University of Zululand. 35 (32\%) who had either indicated that their academic libraries do not offer electronic journals, or were not sure, or did not respond were excluded in this question. The response rate to this question was $22 \%$ for excellent, $59 \%$ for sufficient and $19 \%$ for minimal.

$80 \%$ academic staff respondents and $60 \%$ postgraduate students respondents from the University of Natal and $60 \%$ postgraduate student respondents and $17 \%$ academic staff respondents from the University of Zululand felt that the resource support offered by their academic libraries is sufficient. $67 \%$ academic staff respondents from the University of Zululand felt that the resource support was minimal.

\subsubsection{List of hosts/databases for electronic journals used}

In order to test the knowledge of respondents in accessing electronic journals they were required to list at least three hosts or databases that are used in accessing electronic journals. They were given EBSCOhost as an example. The research question targeted 110 respondents because this was the group which indicated the use of electronic journals in Table 5. 35 (32\%) respondents came from the University of Zululand while 75 (68\%) came from the University of Natal. The respondents from the University of Natal listed more sources than those listed by the University of Zululand. The library staff respondents were also required to list databases of full-text, abstracts and bibliographic information. Unlike the first group they were not asked to list at least three of these, but were just asked to list them according to their knowledge. Also with the second group few databases were listed. It was noted that the lists were not generally accurate, which casts doubt on knowledge of the databases. What can be deduced from this is that the University of Zululand academic library is lagging behind that of Natal in the provision of access to electronic journals.

\subsection{Type of media sufficient for the publication output}

Respondents were required to indicate the type of media that they find sufficient for the publication output. The purpose of the question was to determine the type of media that respondents use for the preparation of publishing their research results. The response reflects $55 \%$ for both media, $39 \%$ for printed media, $4 \%$ non-response and $2 \%$ for electronic media. The Faculty of Law (UZ) was the highest in selecting printed media by $100 \%$, followed by the Law (UN) by $83 \%$, Arts by $47 \%$, Human Sciences by $35 \%$, Commerce and Administration and Science and Agriculture (UN) by $33 \%$ and Science and Agriculture (UZ) by $29 \%$. The Science and Agriculture (UN) was the only faculty to select electronic media by $10 \%$. Most faculties chose both media: Commerce and Administration (67\%), Science and Agriculture (UZ) (64\%), and Human Sciences (60\%). The academic staff respondents from both institutions selected printed media $(50 \%$ and 
$53 \%)$ more than both media ( $42 \%$ and $47 \%$ ), whereas the postgraduate students selected both media ( $63 \%$ and $60 \%$ ) more than the printed media (33\% and $30 \%)$.

4.10. Correlation between high research and publication output and the use of electronic media

Respondents were asked to indicate if according to their opinion there is a correlation between high research and publication output and the use of electronic journals as opposed to other media. The highest response received for this question was $53 \%$ for undecided. $29 \%$ of the respondents indicated a correlation. Results reflect that there is no correlation as the highest number of respondents indicated that they were undecided (53\%) whereas only $29 \%$ indicated that there is a correlation. This means therefore that there is no correlation between high research and publication output and the use of electronic journals as opposed to other media. Visibly, high research and publication output does originate from the use of print media even if used alone.

Table 8. Correlation between high research and publication output and the use of electronic media $(\mathbf{N}=1 / 0)$

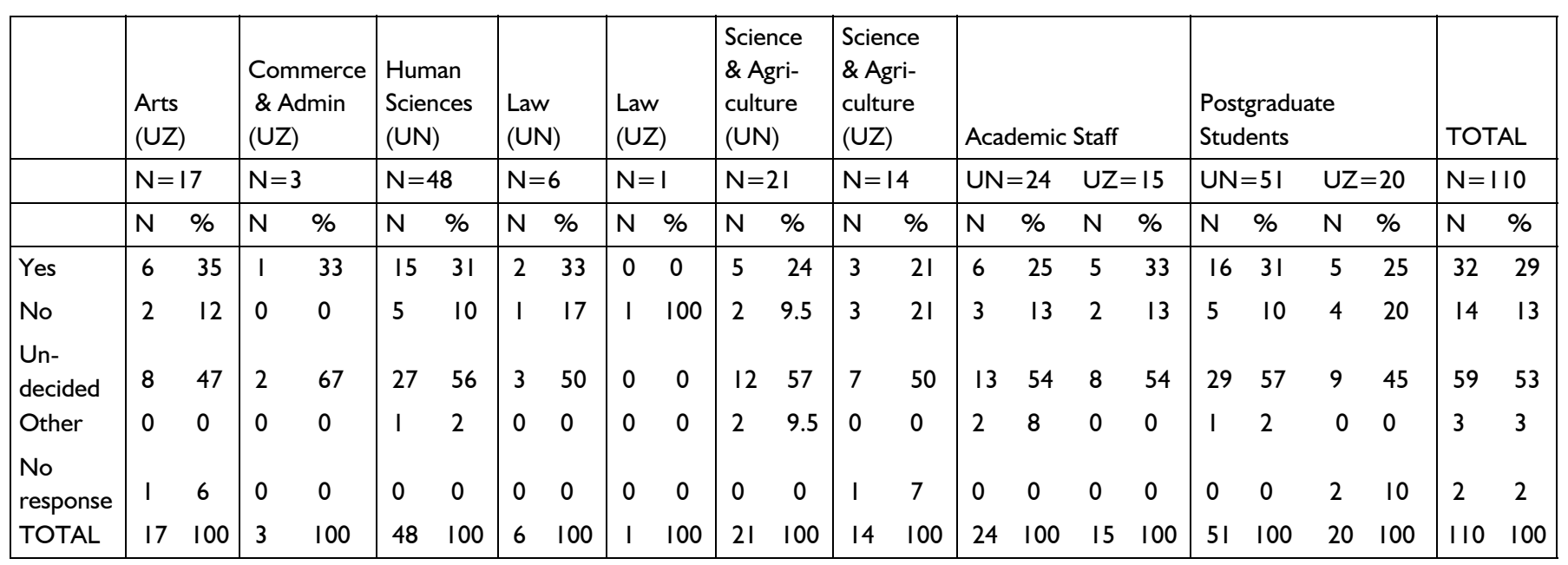

4.11 Perceived impact that electronic journals have on the dissemination of information

The respondents were required to give their own opinions regarding the impact that electronic journals have or may have on the dissemination of information. The overall result indicates a strong perceived impact of $72 \%$. The highest number here indicated a strong perceived impact. The Faculty of Law (UZ) was the highest with $100 \%$, followed by the Faculty of Human Sciences with $77 \%$, Science and Agriculture (UN) with $76 \%$, Commerce and Administration with 67\%, Science and Agriculture (UZ) with 64\%, Arts with 59\% and Law (UZ) with 50\%.

The academic staff respondents of the University of Natal scored more than those of the University of Zululand by $58 \%$ against $53 \%$, but their score was less than both postgraduate student respondents, which were $82 \%$ for the University of Natal and $75 \%$ for the University of Zululand. It is important to note that respondents were giving their perceptions when answering this question. Some even mentioned that electronic journals have a potential impact.

\subsection{Recommendations}

This last item of the questionnaire required respondents to give their recommendations on what academic libraries could do in order to improve the use and exploitation of scholarly journals, particularly electronic journals. The following issues emanated from the recommendations given by respondents from both institutions.

Firstly, it was obvious from the recommendations given by the respondents that they feel that the services, especially electronic services, need to be marketed to the users in order to make them aware of what the library provides. Secondly, it transpired from the responses mostly from the University of Zululand that the services offered by their academic library are inadequate as most of the recommendations concerning the provision of facilities in the library came from them. Thirdly, it was evident from the responses received that respondents felt that there should be thorough research done by the library in order to determine the views of users. Fourthly, user education was also brought up by the responses that were received as the respondents were of the opinion that users need to be educated and trained in the use and the importance of using electronic journals. Lastly, other respondents mentioned the issues of cost implications for electronic journals, which are high subscription charges, as well as cost for printing, thus were in support of the popularity of the electronic journals. 


\section{Discussion}

Although $80 \%$ of the academic staff and postgraduate students from both institutions said that they were using electronic journals, the level of their electronic journal use was found to be insignificant. This was reflected in the responses received for the type of journals that they normally use. It was observed that $61 \%$ selected print journals while only $2 \%$ selected electronic journals. Similarly, when they were required to list at least three electronic and print journals that they use most, a lesser score was given to the electronic journals than to print journals. The level of using print journals was therefore found to be higher than that of the electronic journals. The study, however, was not aimed at comparing the two types of media. In addition, the low level was also tested when respondents were required to list hosts or databases used for accessing electronic journals. Very few respondents were able to provide this information. Respondents were also required to indicate the type of media sufficient for the publication output. Only $2 \%$ selected electronic media. What was established was that respondents who use electronic journals always selected them together with print journals, that is, they opted for both media. This did not obscure the evidence that electronic journals are less used.

Since the impact that electronic journals have on the scholarly community could not be ascertained in this study, respondents were required to give their perceptions regarding the impact. The electronic journals displayed a strong impact. This suggests that in future they might play an important role in the dissemination of scholarly information, which may even supersede that of print journals. It all depends on the advancement and provision of Information Technology by the responsive institutions as well as marketing the services available.

More users felt that electronic journals were easy to access. Users indicated a perception of strong impact, which suggests that their attitude towards the electronic journals is positive and that they will be used more than the print media in future. Respondents who displayed a negative attitude towards the use of electronic journals said that they prefer print journals because they are easier to use.

There is a slight difference between the various disciplines in the use and understanding of electronic journals. The Faculties of the Human Sciences (UN) and Science and Agriculture (UN) rated higher than other faculties by $68 \%$, followed by the Faculty of Science and Agriculture (UZ) by $62 \%$, Arts (UZ) by $61 \%$, Commerce and Admin (UZ) by $60 \%$, Law (UN) by $51 \%$ and, lastly, Law (UZ) by $45 \%$. The ratings were found by adding all scores and dividing them by the number of questions that were relevant to determining the use and understanding of electronic journals. On average there seemed to be insignificant differences between the disciplines as well as between the two institutions on this domain. The $10 \%$ range in favour of the University of Natal is evidently insignificant.

Although the academic libraries have limited resources, they do offer electronic journals to the users. The responses from the University of Natal indicated that they have more facilities than the University of Zululand of offering electronic journals. This was evident in the response rate received from the two institutions, which was $80 \%$ for UN and $51 \%$ for UZ. The responses from the library staff also concur with this, as a 100\% response rate was received from the UN library staff as compared to $75 \%$ received from the UZ library staff. When the Librarians were requested to indicate their purpose(s) of using electronic journals, all choices from the UN library staff included using electronic journals on behalf of the end-users, while at the UZ library $17 \%$ of the responses was for learning. Since learning may be associated with personal development, this means therefore that there are librarians from the University of Zululand who may not be using electronic journals to assist the end-users.

For marketing the existing services the Librarians from the two institutions indicated that they do market their services. The University of Natal library staff as compared to those of the University of Zululand displayed more marketing strategies and skills. Feedback received from the end-users also reflect that the academic libraries do play their roles in assisting them.

The resource support for the University of Natal is sufficient, while that of the University of Zululand is between sufficient and minimal.

Results obtained indicate an emerging relationship between research and publication output and the use of electronic media although it is also still low as compared to print media. This was reflected by the respondents' selections when required to indicate the type of media that is sufficient for the publication output. $55 \%$ of the respondents opted for both print and electronic, $39 \%$ opted for print and only $2 \%$ opted for electronic media. Because there are respondents who use both media, the relationship that electronic media has could therefore not be missed.

\section{Conclusions}

Studies on information seeking reveal that academic libraries, academic staff and students, publishers of academic journals and books have an important role to play in the system of scholarly communication (Milne, 1999). This role was also reflected among the scholarly community of the two institutions. The mission statements of the two institutions revealed that they are engaged in teaching, learning, research and development, which are parts of the scholarly communication 
process. This process involves the use of scholarly journals, which play a role in the dissemination of scholarly information. The scholarly communication system may therefore be transformed by the use of electronic journals, but as Harter (1998:507) cautions, they can only succeed in this transformation if they are integrated in the process of scholarly communication. This integration was found to be lacking in the two institutions under investigation. Although the impact that electronic journals have on the dissemination of scholarly information could not be determined, this study was able to measure the perceived impact from the respondents. A strong perceived impact was found to exist. The level of use and understanding of electronic journals was found to be low as compared to the use of print journals. The scholarly community was found to be more reliant on print journals. There was a slight difference in the use of electronic journals by various disciplines and the two institutions. Studies support the notion that lack of adequate resources and facilities affect the use of electronic journals as technology and equipment may not be affordable by poor libraries and users (Chan, 1999). The findings of the study indicate lack of adequate resources and electronic facilities, particularly at the University of Zululand. This in turn has an effect on the use of electronic journals by the scholarly community concerned. Although University of Natal has enjoyed the privileges of an Historically Advantaged University, there is no strong evidence to suggest their superiority in the exploitation of electronic journals over the University of Zululand. Ultimately, the recommendations suggested for e-journal provision applies largely to KwaZulu Natal Institutions.

This study has noted that provision of IT facilities in the library is essential. Provision of such facilities in the library may enhance the use of electronic journals by users, more especially students. This could be done by having electronic classrooms with sufficient electronic equipment to be used by the users, and a trained person who will always be available to help and train users. Secondly, the marketing of electronic services has not been sufficient. There is therefore an urgent need for marketing the existing services, more especially at the University of Zululand Library, where the library staff respondents indicated very few methods of marketing their services. The marketing methods may include publicising new and existing electronic services through the Library's web page, listserver and intranet, conducting workshops to educate the users on how to exploit the products and services, and through online and printed newsletters. Thirdly, user education is noted to be lacking. The users need to be literate in the use of electronic journals. Some user education and training may be necessary. This process calls for an interaction between the academic staff and the library staff. Having the library staff marketing the services and educating the academic staff on the use of such services could do this. Then the academic staff in turn will be able to pass the information to the students, possibly by recommending to them to make use of the services in consultation with the library staff for assistance. Short courses on the value, availability and use of electronic journals should be offered. Fourthly, the issue of electronic publishing also requires attention. The scholarly community should be encouraged to publish in electronic journals by rewarding publication of that type. It is assumed that this in turn will improve their use and understanding of electronic journals. Fifthly, gaining support from management without selling the services to them is impossible. The library management needs to "sell" the electronic services to the management in order to gain both moral and financial support without which it may not be possible to achieve the required goals, such as providing the comprehensive electronic service. Other issues for attention includes, establishing the position of electronic resources Librarian. The academic library, more especially, at the University of Zululand, should have an electronic resources librarian who will be solely responsible for the collection as well as the management of electronic records and journals. Finally, improving methods of access by creating an alphabetical list of electronic journals available for access by end-users should be provided on the library's home page and access to such a list should be at least one or two clicks away from the library's home page. Registered students and staff should have easy access to the electronic journals offered by the library.

\section{References}

Bandyopadhay, A. 1999. Accessing SCl-tech literature: commercial document delivery services and online full-text databases. Collection Building, I8(I): I0 Retrieved June 9, 1999 from Emerald-Library Database.

Cargille, K.; Degener, C.; Barker, J. W. \& Huang, T. 1999. Electronic journals and users: three perspectives. Serials Review, V25 (3):47 Retrieved March 23, 2002 from Ebscohost Database

Chan, L. 1999. Electronic journals and academic libraries. Library Hi Tech, Vol. 17 (I) Retrieved May 06, 2000 from Emerald-Library Database.

Cook, B. (ed.) 1992. The electronic journal: the future of serial-based information. New York: The Harworth Press

Eason, K.; Carter, C. \& Harker, S. 1997. A Comparative Analysis of the Role of Multi-Media Electronic Journals in Scholarly Disciplines. Retrieved December II, 2000 from http://www.ukoln.ac.uk/services/elib/papers/tavistock/eason/eason.html

Fisher, S. 1995. Access to information. Library Management 16(5) Retrieved August 6, 1999 from Emerald-Library Database.

Getz, M. 1997. Electronic publishing in academia: an economic perspective. Retrieved June 22, 1999 from http://www.arl.org/scomm/scat/ getz.html

Gyeszly, S. D. 200I. Electronic or paper journals? Budgetary, collection development, and user satisfaction questions. Collection Building, 20(I):5-10 
Harter, S. P. 1998. Scholarly communication and electronic journals: an impact study. Journal of the American Society for Information Science, 49(6):507-516

Klemperer, K.. 1999. Electronic journals: a selected resource guide. Retrieved December 6, 2000 from http://www.harrassowitz.de/ms/ ejresguide.html

Kuhlen, R. \& Zhang, Z. 1997. Building web-based scholarly communication forums using electronic journals. Retrieved December 6, 2000 from http://www.dl.ulis.ac.jp/ISDL97/proceedings/zhang/zhang.html

Liew, C. L.; Foo, S. \& Chennupati, K.R. 2000. A study of graduate student end-users' use and perception of electronic journals. Online Information Review, 24(4):302-315

Milne, P. 1999. Electronic access to information and its impact on scholarly communication. Retrieved April II, 200I from http:// www.csu.edu.au/special/online99/proceedings99/305b.htm

Mogge, D. 1999. Seven years of tracking electronic publishing: the ARL Directory of Electronic Journals, newsletters and Academic Discussion Lists. Library Hi Tech, 17 (I): 17-25

Mountifield, H.M. \& van Brakel, P.A. 1994. Network-based electronic journals: a new source of information. South African Journal of Library and Information Science, 62(I): 28-33

Ocholla, D. N. 1999. Insights into information-seeking and communicating behaviour of academics. Intl. Inform. \& Library Review, 31:I 19-I43 Retrieved May 15, 200I from http://www.idealibrary.com

Rao, S. S. 1998. Trends in publishing and delivery of electronic information. New Library World, 99(II45) Retrieved June I5, 1999 from Emerald-Library Database

Sweeney, L. 1997. The future of academic journals: considering the current situation in academic libraries. New Library World, 98(I I 32) Retrieved October 6, 1999 from Emerald-Library Database

SYSTAT Statistical Program, Version 7.0 1997. SPSS INC

University of Natal. 200 la. About Natal University: Facts and Figures. http://www.nu.ac.za/bkgnd/ff.asp

University of Natal. 200 l b. Information: About Natal University. http://www.nu.ac.za/bkgnd/mission.asp

University of Natal. 2000. 38th Library Annual report

University of Zululand. 200 la. Calendar, General. Kwa-Dlangezwa: University of Zululand

University of Zululand. $200 \mathrm{Ib}$. Division of Information Technology

University of Zululand. 2000a. Library Annual Report.

University of Zululand. 2000b. Staff handbook. Kwa-Dlangezwa: University of Zululand

Van der Walt, P.W. and van Brakel, P.A. 1995. Access methods to electronic journals via the Internet. South African Journal of Library \& Information Science, 63(2):56-64

Varian, H. R. 1997. The future of Electronic Journals. Scholarly Communication and Technology Conference Foundation, at Emory University, April 24-25. Retrieved November 12, 2000 from http://www.arl.org/scomm/scat/varian.html

Wells, A. 1999. Exploring the development of the independent, electronic, scholarly journal. MSc in Information Management, $1998 / 1999$. Electronic Dissertation Library. University of Sheffield: Department of Information Studies Retrieved March 22, 200I from http:// panizzi.shef.ac.uk/elecdiss/edI000I/ 